
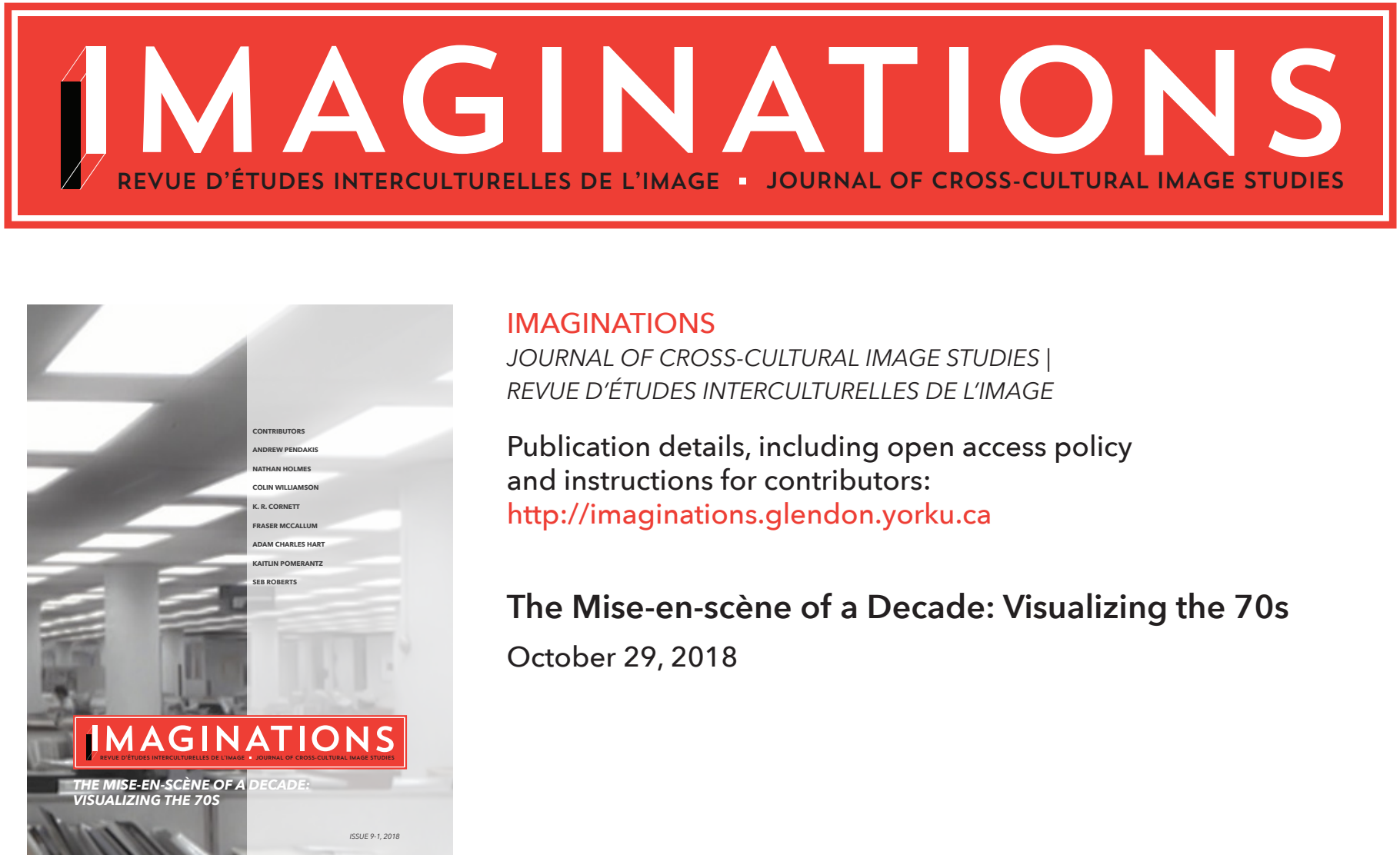

IMAGINATIONS
JOURNAL OF CROSS-CULTURAL IMAGE STUDIES |
REVUE D'ÉTUDES INTERCULTURELLES DE L'IMAGE

Publication details, including open access policy and instructions for contributors:

http://imaginations.glendon.yorku.ca

The Mise-en-scène of a Decade: Visualizing the 70s

October 29, 2018

To cite this article:

Cornett, K. R.. "Predictive Landscapes." Imaginations, vol. 9, no. 1, 2018: Web (date accessed), pp. 41-60. DOI 10.17742/IMAGE.p70s.9.1.4.

To link to this article:

http://dx.doi.org/10.17742/IMAGE.p70s.9.1.4

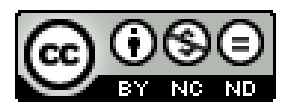

The copyright for each article belongs to the author and has been published in this journal under a Creative Commons Attribution NonCommercial NoDerivatives 3.0 license that allows others to share for non-commercial purposes the work with an acknowledgement of the work's authorship and initial publication in this journal. The content of this article represents the author's original work and any third-party content, either image or text, has been included under the Fair Dealing exception in the Canadian Copyright Act, or the author has provided the required publication permissions. 


\title{
PREDICTIVE LANDSCAPES
}

\author{
K.R. CORNETT
}

\begin{abstract}
The popularity of the road film in the 1970s is often attributed to its updating of the Western film genre, an enduring form in Hollywood cinema. This essay argues that a hierarchical understanding of the relationship between the two genres is detrimental to understanding their efficacy. Case studies of two minor films produced outside of the Hollywood studio system reveals the centrality of landscape and spatiality to generic evolution. While the mythology of New Hollywood Cinema touted a reflexive deployment of genres that perpetuated in Hollywood for most of the studio era, these independently produced films endeavored to imagine an alternative to this ideologically dominant system. This article explores the uneasy balance of subversion and citation of genre to gain an understanding of the complex relationship between authorship, production, and hegemonic practices in this transitional era of American film history.
\end{abstract}

Résumé | La popularité du road movie des années 70 est souvent attribuée au fait qu'il constitue une adaptation moderne $d u$ western, genre éternel du cinéma hollywoodien. Cet essai veut montrer qu'une compréhensio hiérarchique de la relation entre les deux genres de films nuit à l’appréciation de leur efficacité. Des études de cas de deux films mineurs produits en dehors du système des studios hollywoodiens révèle la centralité du paysage et de la spacialité dans lévolution du genre. Alors que la mythologie du Nouveau Cinéma Hollywoodien étalait un développement réflexif des genres qui a perduré à Hollywood pendant la plus grande partie de lère de domination des studios, ces films de production indépendante s'efforçaient de concevoir une alternative à ce système idéologiquement dominant. Cet article explore l'équilibre précaire entre la subversion et le respect du genre afin d'acquérir une compréhension de la relation complexe entre lécriture, la production et les pratiques hégémoniques dans cette ère de transition de l'histoire du cinéma américain. 


\section{FORD GALAXIE}

\section{GALAXIES - GALAXIE 500'S - GALAXIE 500/XI'S - GALAXIE WAGONS}

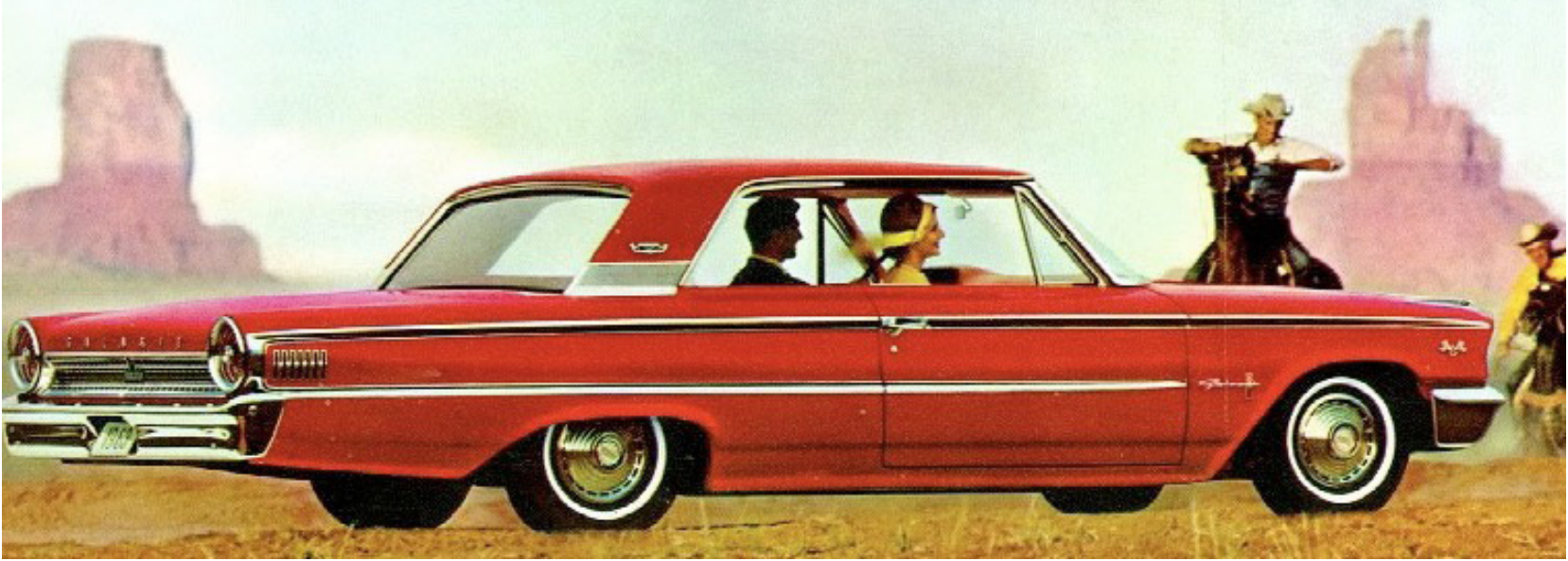

A magazine advertisement for the 1963 Ford Galaxie (figure 1) foregrounds in both its form and content the necessity of restorative nostalgia for America's frontier past in order to contextualize the modern (Harvey). Three iconic images sit in remarkable relation and tension: the landscape, the cowboys, and the automobile. The rock formations invoke the Western landscapes made famous by the filmmaker John Ford, further emphasized by the presence of the cowboys. The automobile sits in the foreground as a kind of continuum of the history of mobility, from horses to the sedan. The specific layout also suggests a particularly modernist anxiety about the function of the past and the necessity for continuity as a key aspect of American identity and culture even as it came to
Figure 1: Advertisement for 1963 Ford Galaxie

a set of crises in the postwar era. This particular anxiety was recognized in the early- $20^{\text {th }}$ century by literary critic Van Wyck Brooks as the desire for a "usable past," a lineage of American culture that would enable cultural production as a continuous practice, part of a domestic tradition that could inform the development of an American ideal that always held individuality and collective identity in careful simultaneity (Cooney 22). The invocation of the frontier landscape and the cowboys also suggests a mobilization of the past itself, a way to bring an important aspect of American identity to bear on the construction of its future. This project of historical specificity, of reconstructing visual iconography in the 
service of a telos of American progress, is central to an understanding of the nostalgic use of landscape in Hollywood Westerns during the Cold War. The function of nostalgia in films of this genre throughout the studio era is strikingly consistent and almost always distinguished by the ways in which landscape is used to suggest the longing not for a bygone era, but rather for a notion of "truth" that is bound up with the authenticity of nature.

In the twilight of the studio era in Hollywood, a dialectic emerged from this simultaneous looking forward and back: a constant consideration of not only the use of the past but the way that this very consideration changed the function of what had previously been taken for granted. This advertisement deploys the iconography of the landscape to make the history of the frontier useful as something more than a static, collective identity-it becomes a useful point of departure, a dynamic origin that suggests any number of American virtues, from ingenuity to tenacity. Americans prospered via their mobility on horseback, passing through difficult terrain to bend it to the will of civilization. The advertisement asserts that in its present of the early 1960 s American industry and prosperity has allowed Americans the leisure and freedom to travel as they please, in a new iteration of the settlement and manifest destiny of the cowboys seen in the background. These three examinations of mass culture-the advertisement, the Pop Art movement, and the Hollywood genre film-operate on this fulcrum of modernity. Informed on the one hand by a tension between the promiscuity of image-based culture and a desire to explore the mediation of mass art, and on the other by a distinct relationship to the past, the movement of mass art from the mid-1950s to the 1960s predicts the aesthetics of the 1970s in an astonishing variety of contexts. While taking up the question of the status of American advertisements and their relation to the Pop Art movement is a tempting prospect, the juxtaposition of the three elements presented in the Ford Galaxie ad present a clear opportunity to think through the relationship between the Western, a genre that seemed to wax and wane in popularity throughout the 196os, and the road film, a genre often thought of as best positioned to capture the zeitgeist of the Vietnam Era. At stake here is the way in which the landscape, represented in the ad as a kind of restorative nostalgia, becomes the defining aesthetic object of the road film in the 1970s.

A brief delineation of terms is in order here, given that the distinction between these descriptors is essential in order to discuss the relationship between the Western and the road film. The concepts of space, place, and landscape are distinguished through their functions, not their denotative meanings but rather how they circulate and interact with each other. Using the Ford Galaxie automobile ad as an example, we can define place as the specific setting of the image, often considered as a background. Notably, the "place" of the ad is self-consciously non-specific: this is the key tension of the term, the precarious status of elaboration. Is this Monument Valley, or somewhere geographically similar, or is it merely meant to evoke this specific location? Place carries ambiguity as one of its defining aspects-it can be all of these things or some combination of them, but it explicitly points to something in particular. Following from this notion of place, space is a location that is made distinct by its political or cultural status; it is defined by interaction and intersections of various practices. Thus, we can think of the space of the advertisement in terms of its presentation that suggests not only particular modes of engagement but also a relationship between these 
modes (the car and the horses). To contemplate the spatiality of an image is to discern what Michel de Certeau describes as "vectors of direction, velocities, and time variables" (117). The space of this ad is strikingly oriented, with the modern car in the foreground of cowboys on horseback. Perhaps the most useful part of this understanding of space as distinctive from place and landscape is the way in which it forces us to contend with the hierarchy of presentation in a mise-en-scène. Here, the sharp dimensions of the automobile help delineate it temporally from the deliberate flatness of the cowboys-the suggested continuum is made explicit in the contrast. Both these figures can inhabit the place suggested by the background; an understanding of the space of the composition gives us a deeper understanding of their respective relations to this background, and therefore to an intended audience. Mobilizing these conceptions to account for the rhetoric of this visual presentation allows for a more active understanding of landscape, the final term in this triad. Engaging with the history and multiplicity of the term is far beyond the scope of this essay; instead, I want to draw attention to the way in which these definitions of space and place innervate the notion of landscape. Geographer J.B. Jackson offers a useful conception of landscape as "a composition of man-made or man-modified spaces to serve as infrastructure or background for our collective existence" (8). The interplay between these terms focuses on the function of landscape, rather than its definition. An active understanding of what landscape does emphasizes Jackson's helpful suggestion that landscape is about collective recognition of a composed space, and the role this space occupies in "not only our identity and presence, but our history" (Jackson 8). The significance of this advertisement as an example does not lie in the relationship between disparate elements, but rather in discerning the telos of the landscape, which is also a significant difficulty of the Western film genre in the postwar era.

This essay engages the question of the use of landscape in terms of form, genre, and political purchase in the context of a particularly fraught era in American history as well as the history of the Hollywood film industry. Both the Western and the road film take location as the central identifier of their genre, as opposed to other genres such as the melodrama, which centres affect, or the blockbuster, with its emphasis on spectacle. Consequentially, both Westerns and road films must in some ways articulate their relationship to landscape, and thus to history, and this is the source of their divergence. The Western posits landscape as restorative. That is, it uses the significance of landscape to perpetuate an idealized aesthetic that is to be longed for (this particular kind of longing is, of course, a more general understanding of "nostalgia"). The form of the landscape is one of reconstruction and ritual-of returning home, completing the cattle drive, and bringing justice and order where there is seemingly none. The endurance of the Western is due not merely to the repetition of these plots, which has also come to define the genre, nor the politically advantageous position wrought by the establishment of law and order as a collective good, but instead the way in which it repeats various landscapes that become symbolic of these qualities. In contrast, the road film tends to present its landscapes as reflective spaces. An emphasis on travel through various places, which gain significance through establishing space, situates the road film as far less likely to engage in the static aesthetics we tend to associate with landscape. Many of these films use landscape as an aestheticizing of this process of negotiating the dynamics of space, place, and landscape. 
Monte Hellman's The Shooting (1966) is an example of a film that has the iconography of a Western but the political and aesthetic sensibility of a road film-a kind of proto-road film that acknowledges a precise relationship between two genres while instantiating a relationship to landscape that predicts the aesthetics of the 1970 s road film. Hellman's film is particularly suited to a discussion of the emergence of a 1970 soad film aesthetic because it so readily and precariously does away with the conventions of one genre while predicting the conventions of another. The Shooting occupies a rela-

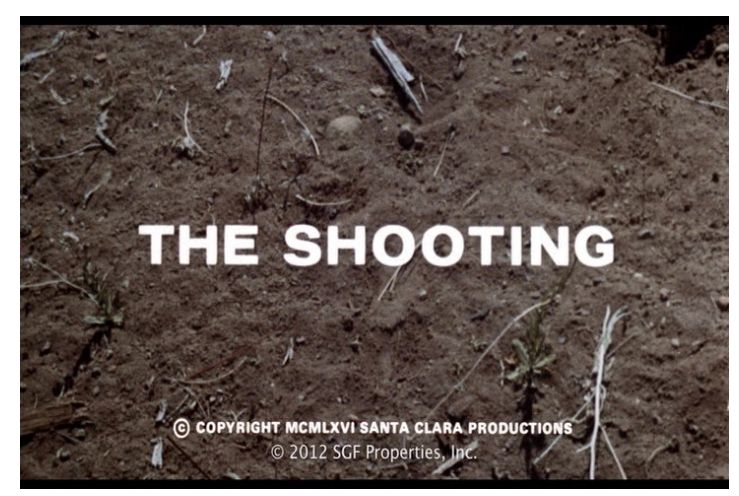

Figure 2: The Shooting-title card

tion to both genre and Hollywood that offers an opportunity to explore the efficacy of both these categories in the post-industrial era. While the Western tends to look back towards history as a legacy to be revered, the road film is about forward momentum. Rather than denying either of these positions to history, The Shooting often elides them both, creating an enigmatic experience that articulates both the limits and the possibility of using spatiality to explore a new aesthetic.

Hellman's film asserts its aesthetic with its unusual opening shot (figure 2), and ends with an enigmatic series of shots that employ step printing. It thus embodies the terms of the road film's relationship to mass culture and a construction of spatiality that is shaped by subjective experience and spectatorial engagement, rather than ideological reconciliation and restorative nostalgia for a coherent America. The plot of the film is deliberately difficult to follow. Ex-bounty hunter Willet Gashade (Warren Oates) and his colleague Coley (Will Hutchins) react with measured skepticism upon the arrival of a character only known as Woman (Millie Perkins). She engages Gashade and Coley as guides across the desolate terrain, having already hired the mercurial gunman Billy Spear (Jack Nicholson) to help her exact revenge for the killings of her husband and son. The motley group travels uneasily toward a tragic conclusion that finds Gashade's fugitive brother and the Woman in a battle of mutually assured death.

Shot with a minimal budget outside the Hollywood studio system, The Shooting has been referred to as an "existential Western," (Bandy and Stoehr, 228) perhaps because its depiction of an increasingly inhospitable environment eventually renders the plot and the actions of the characters irrelevant. Their ultimate lack of choice emphasizes absurdity, and the spectator is left to consider man's place in a universe in which it might be possible that a landscape bears no trace of human existence. The idea of an existential Western seems to resonate in many examples of the genre throughout the 196os, from the spaghetti Westerns of Sergio Leone to the spirited outlaws of Butch Cassidy and the Sundance Kid (1969) and the extreme violence of The Wild Bunch (1969). These examples arrive primarily at the end of the 196os, a context that distinguishes them from the psychological Western cycle that exerted its influence earlier in the decade. The subgenre of psychological Western is limiting in an examination of spatiality because 
of its primary concern with the interrogation of the Hollywood Western. The invocation of the myth of the genre is central to the fascinating ways that these films point to the inadequacy of America's frontier history, but this kind of interrogation means that landscape is largely left to its symbolic origins. From its opening sequence, The Shooting solicits a different relationship to the landscape, beyond reverence but without cynicism. While the so-called existential Western is always positioned counter to the austere postwar Westerns of Hollywood, films such as The Shooting imagine an alternative to the hegemony of the industry.

In her study of texture in cinema, Lucy Donaldson argues that the opening of The Shooting moves "against the grain of a smooth entry into the world, and immediately transmits a sense of roughness and even precariousness" (Donaldson 6). As part of a series of disjointed cuts, this opening frame is either a subjective shot from the point of view of the first character shown onscreen, Willett Gashade, or from his horse, or from both of them. This ambiguity follows the deliberate violation of continuity editing in the previous shots of the title sequence and, in the style of Hollywood films, dictates both tone and mood for the rest of the narrative. The privileging of form over content is not fully realized here, but is certainly suggested in the unsteady framing of dirt, rocks, and a scant suggestion of plant life. This tie to a subjective experience of the world is a moment that expresses texture as "an expression of quality and nature" (Donaldson 1). The combination of overt construction of the opening sequence and the expression of space via texture points to the central dialectic of the film's form: the subjective experience of the world presented in a style indebted to the reflexivity of the European art film, and the acknowledgment of the Western's ideological use of space. While this self-conscious approach to form allows for and perhaps even encourages a particular ambiguity, it also problematizes the status of realism. The style of Hellman's film is less concerned with the appearance of artifice than it is with the privileging of experience. In other words, there is a specific way in which this points to a structuring of landscape that calls the necessity of mainstream genre films' adherence to a kind of looking into question. The Shooting recognizes the versatility of landscape; its value as representation surpasses its use as an assumed framework.

Neil Archer claims, "It is not an exaggeration to say that, for many, the road movie is synonymous with America cinema" (11). This assertion points to the fascinating way in which Hollywood cinema maps onto essential desires mobilized by the medium: the desire for speed, for nearness and distance, and for a sensuality that engages both objective representations and subjective experience. Take Archer's statement along with Andre Bazin's declaration that "the Western is the only genre whose origins are almost identical with those of the cinema itself" (Bazin 140), we come to an essential question: if the Western is "cinema" and the road film is "American cinema," where does this national specificity come from and why is it integral to the definition of the latter genre? This question seems particularly difficult if we assume that the Western is a generic form that is primarily discussed and perceived as having a deep preoccupation with American structures and ideologies.

The claim that the popularity of the road film is at the expense of the Western assumes that both genres occupy a similar role in the environment of industrial American cinema and merely vary their approaches to American exceptionalism. This perspective informs the reasoning behind 
the reception of Easy Rider (1969), for example, as being a kind of modernized Western. The theory that 'they traded horses for motorcycles' (Feeney, 226) in the road film locates the key difference between the two genres in their preferred mode of transportation-the iconography of the horse is simply updated to the motorcycle. Elaine Carmichael concludes that "Easy Rider successfully replaces the time-honored cowboy with two countercultural antiheroes who resolve the waning importance of men on horses during the late 1960s" (Carmichael 148). Actor Peter Fonda also referred to it as "a modern Western" (Biskind 42), and Jack Nicholson observed that the modern-day cowboys are such because they ride motorcycles instead of horses (Engelmeier, 104). These facile understandings of the significance of the Western threaten to relegate the road film to a subservient role as the updated version of a genre that has enjoyed far more critical scrutiny.

Films that feature automobility have been as significant to the development of cinema as the Western because the medium is concerned with not only realism but with the process of movement through space. Thus, we can appreciate the ways that the Western's use of location shooting encouraged various understandings of cinematic realism in the same way that the road film's obsession with movement and speed contributes to the cinema's complicated and fascinating relationship not only with modernity but everyday life. In this sense, the road film cannot replace the Western because its relationship to technology has entirely different priorities. Moreover, the Western is not unsustainable given its relationship to modernity and the modern, and thus cannot be said to be replaced by the road film. In other words, it is not the Western's anxiety about or inability to represent modern life that causes it to wax and wane in popularity, as the plethora of psychologically complex examples of the genre attest.

The road film does not emerge from the waning of Western, but rather from the constant repositioning and re-articulation of daily life in modernity. The political positioning of the road film vis-à-vis dominant ideology is its most significant distinction from the Western, while the relation to the American landscape is the primary point of convergence for the genres. In one of the few books to engage with the road film, Steven Cohan and Ina Hark figure the basic dialectic of the genre as a tension between individualism and populism, with the specific aim to "imagine the nation's culture" (3) as either coherent or disjunctive space. This attempt to reconcile both the political aim and the nature of spatiality in the road film as something distinct from the Western is ubiquitous in scholarly discussions of the genre. The tension between socalled "conservative values" and "rebellious desires" (3) marks the road film as distinct from the Western. David Laderman figures the aforementioned dialectic as "depoliticized" (3), while film critic Michael Atkinson notes, "Road movies are too cool to address seriously socio-political ideas" (Atkinson 16). Yet scholars also cite the spaces of the road film and the nature of its approach to narrative as evidence of its political tendencies; the films either "define the road as a space that disavows virtues extolled by the Western" or "take over the ideological burden of its close relation, the Western" (Cohan and Hark 12). In other words, the road film permits a political position that is contrary to the political position of the Western but also grapples with similar ideological tensions that, according to a number of scholars, are based both in the complexities of gender politics and the reconciliation of historical context. Indeed, both Timothy Corrigan and Shari Roberts note the centrality 
of gender to the road film. For Corrigan, "the contemporary road movie responds specifically to the recent historical fracturing of the male subject" (Corrigan 138), as if this crisis were an unusual symptom of a particular era in film history or a concern that was somehow exclusive to the road film. In an essay about the road film included in the influential The Road Movie Book, Shari Roberts contends that the relationship between the Western and the road film is based in a specific understanding of an "ideal of masculinity" (Cohan and Hark 45), following Jane Tompkins' astute observation that "the Western is about men's fear of losing their mastery, and hence their identity" (Tompkins 45). While these discussions contribute helpfully to articulating common features of both genres, they do not necessarily elucidate why this association is helpful beyond offering a facile theory for their historical ebb and flow. The combination of the foregrounding of modernity and its inherent social crises with the potential for space to operate as something other than an ideological ideal or nostalgic background is the basis for the appeal of the road film, which is often more self-conscious about the relationship between spatiality and political ideology.

There is also the matter of context and generic evolution in considering how the road film is often characterized as occupying a space in American film culture that had been reserved for the Western. Although the Western is notably consistent in its use of iconography and the deployment of capitalist ideology throughout the history of Hollywood cinema, it is far from monolithic. Discussing Stagecoach (1940), Bazin recognized an emergent self-consciousness in the genre that shifted the "balance of social myth, historical reconstruction, psychological truth, and the traditional theme of the Western miseen-scène" (149). In this understanding of the specific concerns of the Western, the austerity of the genre throughout the immediate postwar era took precedence over the continued exploration of some of the most fascinating contradictions and ideological inquiries that are realized in films such as High Noon (1952) and Bad Day at Black Rock (1955). The significance of the televised Western should neither be underestimated nor misunderstood in moving the discussion of the movement of the genre out of its primary role as a mythical standard for Hollywood cinema. It is not simply that the televised Western made moviegoers less likely to patronize their big-screen counterparts, but rather that this was a symptom of a much larger change in American life. The postwar years in America ushered in unprecedented prosperity to a growing middle class that began to diversify its leisure activities in new domestic spaces that were often situated far from city spaces. Televised Westerns offered iconography and thematic consistency in episodic narratives that perpetuated the most traditional virtues of America, from the centrality of family life to the ultimate authority of the rule of law. Scale and spectacle were the way forward for Hollywood Westerns, as the star system promised typecast cowboys and the films became increasingly concerned with confirming their origins.

As with most Hollywood feature films, the opening sequence suggests a thesis not only about the ideologies the narrative puts forth, but a specific subject position as well. The opening shot of Shane (1953, figure 3) offers a way to understand an important aesthetic distinction from The Shooting. The landscape featured in the opening shots of Shane is immediately looked at by a character in the frame, played by Alan Ladd, who pauses in reverence, inviting the audience to follow suit. In contrast, the shots that occur before the title card of The Shooting feature a medium 




Figure 3: Shane-title card

close-up of the profile of a horse, who is shown looking straight ahead. It is notable that this position is separate from the spectatorial position; this is the most significant point of comparison between two films as disparate as Shane and The Shooting. Classical Hollywood cinema often insists on the audience's identification with the protagonists of the narrative and does so by simultaneously presenting the look of the camera with that of the main characters. Given the incredible consistency of this subject position and its conflation with the position of the spectator, the opening of Shane is an important example of how the Western can use the picturesque landscape to suggest not only the primacy of Alan Ladd's gaze but the implication that the spectator's look is aligned to and affirmed by the miseen-scène. Of course, this structuring of identification is not exclusive to the Western, but the role of landscape as an ideological symbol is one of its most generative features.

What is predictive about the opening of The Shooting is the way in which it presents the ambiguity of landscape as its central aesthetic. The slight jump cuts used to depict Gashade making his return to the mining camp indicate a self-conscious relationship not only to spatiality but to temporality as well. This reflexive approach bears the early influence of the European art cinema and traces of authorship that most Hollywood studio films would efface. Both Hellman's narrative and aesthetic experimentation arrive at a transitional period in the history of Hollywood cinema, when the industry underwent profound changes as a result of a number of factors, including the aforementioned shifts in mass culture and leisure activities toward driving and automobility as well as the import of foreign films that were less inclined to appeal to general audiences. The landscapes in The Shooting function similarly to the landscapes of a cycle of road films in the 1970s, as a way of working through the unfamiliarity of what should be familiar. If the very notion of landscape depends on curation and composition, then an alternative does not have to call this practice into question so much as it must determine the ultimate function of its aesthetic. Many 1970s road films begin with this essential question: what is there to make of the constant imperfection of an encountered landscape? From this, we get the terms of the wanderlust and determined travel of films from Easy Rider (1969) to Bonnie and Clyde (1967), Badlands (1973) to Two Lane Blacktop (1971). Central to this question is the absence of the status quo, the desire to rebel against the hegemony that perhaps informed the vectors of various roads. If we see the characters in these films as desirous of a coherent subject position vis-à-vis an incoherent American identity then we would conclude, as many critics and scholars have done, to see them as failures. We can leave this project to the romanticized New Hollywood Cinema, where the likes of Chinatown (1974) and Taxi Driver (1976) quote the French New Wave and flaunt their auteur status in search of a new legitimacy. If, however, we locate the priorities of the road film in its relation to the 
difficult work of asserting an identity and presence to reconcile with history, and recognize that this work happens in the significance of landscape, we can begin to understand how an emphasis on the quotidian, the texture of everyday life, becomes a political choice. The Shooting may not take up this project in its entirety, but it does imagine its possibilities. Its small-scale production, outside of the studio production, positions it as a marginalized cultural object in the same way that the " $\mathrm{B}$ " Western formed separately from Hollywood Westerns.

If the Hollywood Western can be considered a dominant genre in American cinema, then an argument can be made that the road film represents a minor tradition of this mode of filmmaking. In order to think through the political purchase of the road film, I adapt the term "minor" from Gilles Deleuze and Felix Guattari's work Kafka: Toward a Minor Literature. In their conception, a "minor literature" is a work that originates from the margins while using the language of the centre. If we understand The Shooting as a proto-road film and not merely a subversive or existential Western, we can acknowledge the significance of the ways in which it "stutters" (to use Deleuze's term) (Bogue 21) the centred ideology of the Western. The film engenders a kind of amorality that exists in the road film, for example, rather than the potential for immorality that exists in a Western. To discuss a film such as The Shooting purely in terms of its deviance diminishes the political presence of morality, which is precisely the mode in which the road film often operates. The idea of the "stutter" supposes a mode of expression that both escapes a dominant system and reifies its decomposition; it is not that the Western is obsolete, but that a new language can be discerned in its decay. Deleuze and Guattari construct a way to use the implication of this theory to consider not only the differences between minor and major artistic practices, but also to suggest that there is genuine significance in the specificity of the minor practice. They acknowledge the subordinate relationship of the minor to the major, insisting that the process of deploying the constructs of the major (rather than developing a distinct language) is the defining trait of a minor literature.

Deleuze and Guattari outline three characteristics of minor literature, which are all relevant to the road film and its status both in relation to the Western and to the construct of Hollywood cinema as a cultural phenomenon. The first characteristic is concerned with the occasion for a minor literature: for Deleuze and Guattari, this is motivated by a desire to deterritorialize language. Various impossibilities challenge this ambition: "the impossibility of not writing, the impossibility of writing (in an adapted language), the impossibility of writing otherwise" (16). While The Shooting is not a revolutionary film, nor one that thoroughly addresses the ramifications set forth by the minor literature concept, there is a tangible sense that Hellman's film conveys these sensibilities. Given its iconography and emphasis on the American landscape, the film suggests a Western; as such, it must situate itself in a certain consciousness of the genre. Given this awareness, it is impossible in this context not to acknowledge the collective perception of the Western, despite (or perhaps especially because of) the skepticism towards the genre as it has been expressed both in Hollywood cinema and in the psychological Western. Distinct from the "A" Western, the psychological Western is distinguished by its fatalistic, obsessive subjectivity and its alienated protagonists. Where these films are often marked by their disillusion with the dominant norms and ethics as dictated by Hollywood ideology, the road film bears some traces of this sensibility. 
The primary tension in the cycle of American road films made between 1969 and 1974 is one of legibility: how to express the desire for an alternative political position using language that exists largely to perpetuate rather than createthus, this desire is impossible to articulate. This "stutter" occurs in the conclusion of The Shooting. As the characters race toward a vaguely defined figure in the steep terrain, the sound of gunshots echoes over a step-printed series of shots. For this brief period, spatiality expresses temporality and conveys the subjectivity of the event. These disorienting cinematic techniques imagine a spectatorial experience in which affect is central.

The second characteristic of a minor literature concerns its position within the dispositif of American society and culture. Deleuze and Guattari describe minor literature occupying a "cramped space" as opposed to the expanse of a "social milieu serving as a mere environment or a background" (17). Individual concerns are always the concerns of society at large in major literature; the subjugation of the personal to the collective is one of the primary ways in which Hollywood cinema presents repetition as difference. The cognitive focus of classical cinema turns on a systemic series of revelations of any number of coherent, denotative possibilities. Politically, these possibilities enhance the illusion of individual choice, suggesting that what characters want at the conclusion of a Hollywood film is ultimately what will benefit society at large: marriage, bringing a criminal to justice, the return to a mutually agreeable equilibrium, etc. The sense of political scale in a minor cinema is fundamentally different, presenting the "cramped space" of individual conflict as the integral issue. In The Shooting, the Woman's desire for revenge is singular and personal. The conflict between this character and Gashade cannot be understood as a symbolic clash between vigilante justice and the rule of law, where both could be satisfied with the same outcome. Gashade's opposition is personal, not political; it is his brother who is being pursued, and the fact of guilt or innocence is irrelevant. The Woman wants retribution not to uphold the rule of law, but to satisfy her own desire for vengeance. Although Will is clearly fascinated with her, she has no romantic or physical connection to any of the characters; she does not seek their approval or make any attempts to domesticate their environment. By the conclusion of the film even the expansive beauty of the American landscape seems to be in inarticulate opposition to the inhabitants depicted onscreen, neither ideal vista nor admired wilderness. In minor cinema the personal is political, to borrow an integral phrase coined in the wake of various social movements of the late 196os. The characters in The Shooting are not the archetypes often observed in the Western, but rather individuals whose connection to the political is not necessarily predicated on the norms of American society. From Gashade to Billy Spear, the Woman to Will, the isolated characters have little relation to social and systemic issues; if the film had aspirations to a major cinema, each might have a trait or motivation that functioned to reinforce or represent a significant aspect of the dispositif. This characteristic of minor cinema is often attributed to a general malaise or sense of alienation that is one of the defining traits of 1970 s American cinema. The idea that conflict or character motivation as experienced by an individual character is symptomatic of a pathos of failure, as Thomas Elsaesser claims, is an example of the necessity of understanding independent American cinema in political terms. The assumption that the characters represent exceptions to the norms of mass culture also assumes that the political position of these films to dominant culture is the 
same as films made within this dispositif, which limits the ways that we can understand the political terms of independent American cinema. Deleuze and Guattari quote Kafka in their description of this second characteristic of minor literature: "what is there (in a major literature) a passing interest for a few, here absorbs everyone no less than as a matter of life and death" (Deleuze 17).

The third characteristic of minor literature-or cinema-is bound up with earlier discussions of the significance of vernacular and its relationship to the Western. The Western bifurcates along industrial lines, between the event-oriented " $\mathrm{A}$ " Western and the vernacular "B" Western. The latter demonstrates a distinct relationship with contemporary popular culture that attempts to account for its shifting function in American society, while the Hollywood Western continued in its invocation of certain generic tropes. The term vernacular suggests not only common usage but a particular deployment in terms of contemporary popular culture, which is hardly static. Given its smaller scale and greater accessibility, being shown on television or as part of a double feature, the " $\mathrm{B}$ " Western is in a far greater position to function collectively. Deleuze and Guattari assert that "because collective or national consciousness is often inactive in external life. . .literature finds itself positively charged with the role and function of collective, and even revolutionary enunciation" (17). The notion of collective expression seems in contradiction to the previous tenet of a minor literature, which places individual narratives at the centre of a minor work. It is precisely these individual narratives, however, that emerge as a kind of collective voice by virtue of their mass accessibility and given the ways in which these narratives engage with 'the people's concern' (Deleuze 18) rather than a 'literature of masters'
(Deleuze 17) . It is no coincidence that Monte Hellman's work has benefitted from the enthusiasm for auteur theory, having arrived at a moment in the history of film criticism that championed the director as the ultimate architect of a film. The auteur theory is a consequence of a tradition of spectatorship that finds meaning in the excess of cinematic expression; it privileges the oeuvre of a film director over an individual film. In this sense, Hellman can be described as a kind of master, given the way in which his work has maintained its significance in no small part through an effort to understand his aesthetic concerns as they manifest in several films. Hellman's partnership with Roger Corman, one of the most influential independent film producers in American cinema, is key to understanding the collaborative spirit at the core of The Shooting. The balance between the authority of the director, the industrial ethos of the producer, and the dedication of the cast and crew on these films anticipates the complex relationship minor films have with spectators and the changing audiences of the era.

A singular narrative can engage with everyday life precisely because it places the individual voice at the center of its expression. Spectators can innervate their experiences with cinematic narratives that are more concerned with the relationship of the individual to a collective than with a perpetuation of the status quo. Thus, our understanding of The Shooting has less to do with its position to other Westerns than to what it has inherited from the genre. The ways in which we might make sense of the narrative corresponds to our relation to the public sphere rather than the inverse. It is the collective understanding of an individual narrative that drives a minor cinema-the road film genre is the product of this mode of American cinema. The focus of a minor cinema is not the known quantity 
of dispositif but rather the potential of a collective that is focused on the possibility of counter-terms of engagement. We can understand the minor cinema of the road film as a further deterritorialization of the psychological Western's interpretation of its dominant genre. Both genres use the language of the Western specifically (and Hollywood cinema more generally), but their approaches are distinctive. The psychological Western often works in a symbolic register, presenting space and landscape as an expression of the limits of the cinematic language in use. In contrast, the road film foregrounds the poverty of this language, abstracting the use of space and landscape, interpreting narratives of travel and civility in terms that engage both the limits of major language and the possibility of viable alternatives.

By emphasizing both the vastness of the landscape and the diversity of its features, The

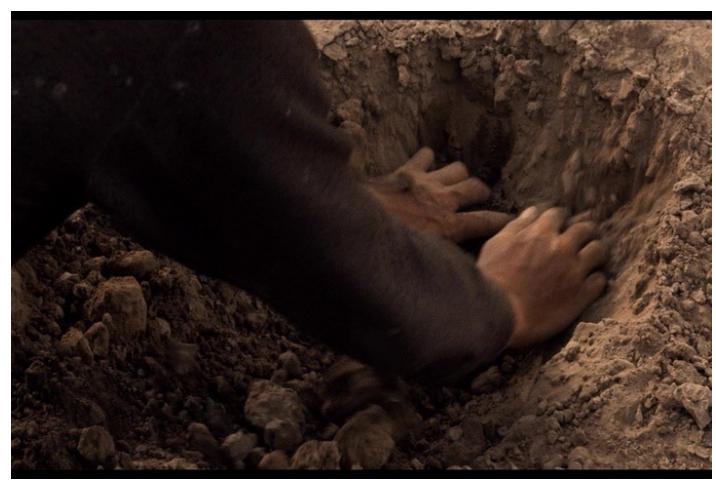

Figure 4: The Shooting-Gashade's hands it is an emphasis of an immersive representation of space.

Whether the Hollywood Western uses landscape as nostalgia or allegory or both, it still insists on the auratic distance between its representation of America and the experience of the space by various characters. The Shooting challenges this hierarchy of perception where the spectator is rarely privileged in two distinct ways: by emphasizing the landscape's potential to antagonize sentient life regardless of mastery or natural predisposition, and by refusing to participate in the pictorial use of landscape that is an integral point of departure for the Western. Because the landscape itself is presented as the defining conflict of the film, these two challenges to the genre negate the centrality of the law in the Western and indicate, most importantly, that it shares more with the road film Shooting uses the haptic to quite literally ground its realism in the affect of the terrain. Gashade's hands trawling through the dirt in a pivotal moment: the earthy depiction of the Woman's disgust at the accumulation of dust and dirt on her face and the trail of dirt from Coley's horse as he rides in pursuit of the hired gunman who will ultimately murder him (figure 4). These images contribute to the realism of the world by the nature of their bodily interaction with the landscape. This foregrounding of bodily engagement with the natural features of the landscape is less about the manifestation of ideological tension and the internal status of the protagonist than than the Western. If we understand The Shooting as part of a particular cycle of Westerns that were made and exhibited during the 196os, then the idea of the existential Western and its association to the film is supported by its relationship to the Western and its articulation of the features of the genre. That is, the presence of horses, a revenge plot, and the vast expanses of windswept terrain are evidence that The Shooting is a Western. Yet its position with respect to lawlessness, for example, is not discernible because of its basic unconcern with a specific and dominant ideology. Its relationship to civil society, whether reluctant acceptance, deep yearning, or a kind of oscillation between the two, is 
also secondary. If the Western is indeed a cyclical genre, if it consists not of members but rather iterations, the genre is complicated beyond recognition by The Shooting. Even if the Western is refined by films that share common features, it is also distinguished by the negation and subsequent substitution of these same features

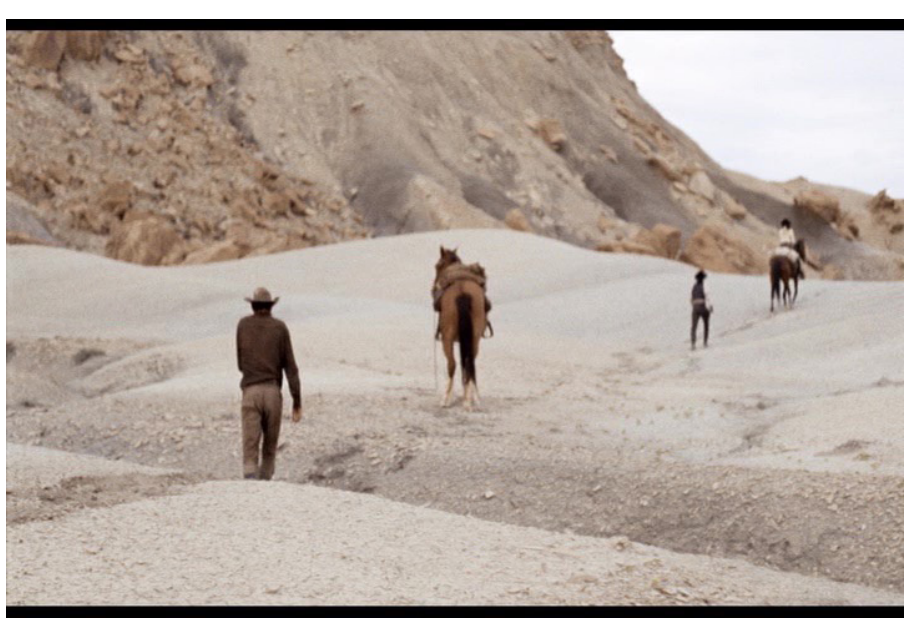

Figure 5: The Shooting-walking across desolate terrain

in another genre. Thus, The Shooting may inherit the desire for retribution from the Western's obsession with justice, but it negates the necessity of law and order with its articulation of indifference, which is made manifest both in the journey of the characters and the numerous shots of humans and horses withering in the unyielding environment.

A composition that occurs late in the film has the last surviving horses and humans trudging towards a conclusion that is neither predictable nor necessary (figure 5). Instead, the journey itself is of crucial importance; having lost their way metaphorically and physically, the only option is to struggle against inertia. This description applies to The Shooting and the road film in equal measure. David Laderman characterizes the road film of the late 1960s and early 1970 s as "focusing on existential loss more than social critique. In this more existential focus, the genre's core conflict with conformist society has been internalized" (83). Throughout his discussion of the existential road film Laderman conflates internalization with political apathy as if a preoccupation with subject position precludes other socio-political issues. The Western often has a similar kind of anxiety about the relationship between self and society. While the bounty hunter or the vengeful gunslinger are determined to assert their identity in relation to society, they are still bound by social rules and rarely act in opposition to the ideology informed by these rules. The tension between individualism and assimilation is often figured by the protagonist's position to domesticity (symbolized by a female character) and resolved in terms of an acquiescence to the rule of law and society. The presence of society and its bearing on the characters in The Shooting is difficult if not impossible to discern; the film is not concerned with law and society, but rather to the primacy of the subject and its experience of space. Thus, we can allow that the performance of self that is essential to the Western is perhaps internalized while making an important observation about the road film. Both genres can perhaps be said to have a conflict with what Laderman calls "conformist society," but it is the situating of this conformist society that The Shooting represents in its landscapes. Inviting a look but unable to accommodate specific intervention, the pictorial landscape is the province of the Western. The textured landscape is essential to the road film precisely because it encourages specific intervention. The terms of this intervention are shaped by the haptic relationship to the environment as experienced not only by the characters in a film like The Shooting but as perceived by the spectator as trace, as an opportunity to engage 
with the landscape image in terms of experience rather than invocation. In the mise-en-scène in figure 5 , the characters and horses cross a rugged, sandy expanse at the foot of a large rock formation, moving toward an unknown destination. Their only path is made by their own experience, by their movement through the space-a trench of sand cuts through the lower half of the mise-en-scène, suggesting a road not taken. Travel is insistently contingent in road films, the substitution for the static presence of law and society in the Western, and thus the two genres have fundamentally different political functions. The cultural critique of the road film is bound up with the assertion that the experience of one's own movement through space is akin to an American ideal, where the Western features iterations of movement toward the same destination, the perpetuation of a static American ideal. Examining Wim Wenders' Kings of the Road (1976), Deleuze and Guattari describe the relationship between two types of voyages: "voyage in place" (physical) and interior/subjective voyage (mental) are not distinguished by quantifiable distance or motion, nor by virtue of a specific cognitive process, but instead by "the mode of spatialisation" (532). While the road film can accommodate either of these modes, the description of spatiality as a mode is useful in understanding the particular significance of landscape for the road film.

Stanley Cavell's theory of genre offers a productive way to account for the political discrepancy between subversive Hollywood films and ones that position themselves alternatively. The common inheritance of mythology central to Cavell's understanding of genre-as-medium turns on the idea that this shared mythology permits interpretation of a myth. The distinction is that genre-as-cycle invokes the myth without interrogation, whereas the notion of genre-as-medium relies on a shared interpretation of a myth. This interpretation adapts Cavell's claim that "a performance of a piece of music is an interpretation of it" (Poague 33). Like jazz, a musical genre that often improvises recognizable structures, the psychological Westerns offer this possibility through subjectivity and the presentation of landscape as a symbol of this subjectivity. The Shooting is an exemplary film that offers an interpretation of the Western's mythology in the same way that jazz departs from traditional arrangements of popular songs. A key component of the traditional arrangement of landscape in the mythic Western is the relationship between Americans and their landscape; conflict is figured in the tension between the awe of natural space and the necessity of its subjugation so that civilization can flourish. The Shooting interprets this conflict as one that does not require the rule of law (a condition for a civil society), and instead offers a dialectic between man's insatiable desire for domination and the indifference of nature or the near-hostility of the landscape. This substitution moves the film away from the Western genre towards the road film, which is obsessed with the threat of ennui rather than the promise of domesticity.

In October of 1971, a million cars were sold in the United States. Automobility was an integral part of life in America, yet the same kind of pessimism that informed popular culture in the wake of the Vietnam war seemed to threaten the role of cars and highways in the contemporary milieu. The traumatic effect of the Vietnam War on the American consciousness arguably found its way into many films in the New Hollywood canon. Christian Keathley's identification of a cycle of films between 1970 and 1976 as a negotiation of "powerlessness in the face of a world whose systems of organization (both moral and political) have broken down" (293) emphasizes 
the war as a catalyst for this crisis. Bob Rafelson's Five Easy Pieces (1970), mentioned in Keathley's essay, explicitly comments on the status of automobility, landscape, and trauma in one extraordinary sequence. Five Easy Pieces is one of any number of independently produced films from the era that attempts to represent various mythologies at stake in an America in which choice is represented as ineffectual. Critical work in response to Rafelson's film considers the historical moment of its release and the various ways in which the protagonist presents a specific crisis of masculinity in response to the aforementioned political crises occurring in various capacities worldwide.

Filmmaker Henry Jaglom notes of his work with independent production company BBS in the early 1970s, "We wanted to have film reflect on our lives, the anxiety that was going on as a result of the war, the cultural changes that we were all products of" (qtd. in Biskind 77). The aesthetic response to various contemporary anxieties in the cinematography of Five Easy Pieces is clearly manifest in a 15-minute sequence that occurs midway through the film. Bobby Dupea, the drifting protagonist of the film, travels with his girlfriend Rayette towards his family's home in the Pacific Northwest. During the trip they encounter two women fixing a car on the side of the road and pick them up as hitchhikers. Terry, the more talkative of the hitchhikers is portrayed by Toni Basil, a choreographer and veteran of avant-garde director Bruce Connor's experimental dance film BREAKAWAY (1966). The camera shows the four inhabitants of the car from the front of the vehicle looking through the windshield. Bobby makes small talk with the two women; Terry notes that she is bound for Alaska. When he inquires further about her destination, her traveling companion replies that Terry wants to live there because "it's cleaner."
Bobby's incredulous response ("Cleaner than what?") is the catalyst for the editing and plot of the rest of the sequence. The film posits an answer to the rhetorical question: the "what" is indicative of the status of American automobility and landscape in the early 1970s-road travel has affected the environment to the extent that understanding the continuity of these changes is not only impossible but of little import. The resignation to a landscape that is populated by infrastructure created for transit fuels both Terry's active rejection and Bobby's wanderlust, an embodiment of the transitory nature of the landscape.

Discontinuity, chance, and incoherence-all devices of fragmentation and modernity-are presented in the crisis of representing the American landscape in Five Easy Pieces. The sequence is punctuated by edits that establish and emphasize the discontinuity of events involving the four characters during their travels together. Terry's rant about "crap" is not edited in the kind of active, causal chain typical of Hollywood films, but rather it is edited by affect, the emotion of the speaker and the dynamic within the vehicle. Terry states, "Pretty soon there won't be any room for man"; the mise-en-scène pointedly shows a barrage of road signs and motel billboards. At various points in the sequence, each inhabitant of the car is shown in their own frame, performing an action that portrays their solitude and the tedium of the journey-Terry smokes a cigarette, Rayette styles her hair in a mirror. Five Easy Pieces further advances the notion of automobility as anxiety and obligation that is central to this iteration of the road film, as if compensating for the representation of road travel as freedom that is absent from the genre in the wake of cultural, industrial, and aesthetic changes. The ineffectuality of many protagonists and the thematic narratives of alienation are, in 
the particular instance of the road film, bound up with the representation of landscape. In road films before this "landscape" cycle, the ambition to travel and the freedom of mobility was often represented in terms of scale, for example, showing a lone car speeding down a seemingly unending road, or by the discontinuity of physical features of the land: vast deserts, massive rock formations, jagged mountains. The vague political and cultural sense that America should have done better, however, is not an inherent feature of landscape, and it is worth noting that the ideologies inferred by these previous representations are not problematized by narrative or the act of travelling through the past, but rather interrogated in terms of the relationship between the road and its surroundings.

In other words, the representation of landscape necessarily changed because of a figurative shift in the political realities of life in America, and it changed materially because roads themselves began to proliferate independently of their surroundings, eventually affecting the environment. John Jerome's The Death of the Automobile (1972), one of a number of books published in the early 1970 expressing concern with the dominance of automotive travel in America lamented that "We stopped building roads to places. We began building roads for automobiles" (qtd in Lewis and Goldstein 398). Bob Rafelson acknowledges this resistance to vehicularity and its effects on the environment in the road travel sequences of Five Easy Pieces even as he notes in the director's commentary for the film that "ecological writing (wasn't) very fashionable at that point." Ralph Nader's Unsafe at Any Speed (1965), an immediate bestseller, was instrumental in new automobile safety laws. Several books such as God's Own Junkyard (1964) to The Death of the Automobile (1972) express a general concern with the size, speed, and availability of cars, recognizing a pivotal moment in the history of the automobile in America.

The car-rant sequence in Five Easy Pieces, defined by its excess to the larger concerns of the film, is remarkable because it endeavors to look outward in an era that largely did the opposite. The landscape becomes a consequence of increased road travel-a symbol of an America that is explicitly defined by capitalist opportunity rather than the potential for settlement, as depicted in the Western. Terry makes a distinction between dirt and filth, the former being a natural phenomenon and the latter a consequence of the encroachment of civilization. Because the kind of looking solicited by landscape is a combination of experience (collective and individual) and discourse, its deployment in the road trip of Five Easy Pieces, a post-traumatic film of the 1970s, is inevitably changed by a revisionist spirit that is in turn affected by the prioritization of realism in American cinema in that historical moment. Landscape is not threatened in these films, given its status as a formation that responds to a need to define and see America and perhaps despite the desire to reinterpret the implied mythology of the land. Cinematographer Lázló Kovacs observed that in Five Easy Pieces Rafelson "never moved the camera on an exterior (shot)," (Schaefer and Salvato, 190) preferring to use montage to suggest movement. Regardless of the subjectivity of the experience of landscape, the desire to portray the road as a steadfast system of organization in the midst of transitory politics and shifting aesthetics remained. The composition of the landscape in the road film is anchored by the system of roads; it is not nostalgia for a disappeared experience of mobility but rather expreses a wistful desire for order.

The establishing shot of the enigmatic final sequence of Monte Hellman's Two Lane Blacktop 




Figure 6: Two Lane Blacktop-Establishing shot, final sequence

(1971) provides a composition that his earlier film, The Shooting, predicts (figure 6). A low camera angle looks out onto a sprawling runway; the black streaks along the asphalt suggest not only prior movement but also velocity. The white dividing line splits the mise-en-scène precisely, depicting the moment of possibility in a space that is defined by such moments. In the same way that The Shooting invites the spectator to engage with the texture of soil and dirt, this shot fosters a desire to push forward, to continue that most cinematic imperative-to move. The 1970s road film is perpetual and oriented towards the future. It is not concerned with the uncertainty of "possible community," but instead encouraged by various potentials of "collective assemblages of enunciation" (88). This tendency is often intertwined with criminality or at least an active resistance to societal norms in a variety of road films from the Vietnam era. Conventional readings of films such as Bonnie and Clyde (1967) insist that "political frustration and disillusionment get internalized by characters (and) dramatized as individual psychological and emotional conflicts" (Laderman 86) without considering the way in which the film is about the struggle to create rather than communicate. Understanding the aesthetic of the road 
film as a genre that foregrounds the landscape is integral to understanding that the remarkable feat of films from Easy Rider to Badlands is not their disdain for the mainstream but their ability to imagine an ideology that has no interest in invoking this mainstream at all. The space of the road film is charged with this potential, from the iconography of gas stations to the scroll of pavement along a seemingly endless road. These vernacular spaces, now in a landscape that invites active participation rather than static reverence, have the potential to represent lived experience in ways that the collective ideologies of Hollywood films, separated as they are from politicized daily life, cannot.

\section{Images}

Figure 1: Advertisement for 1963 Ford Galaxie

Figure 2: The Shooting-title card

Figure 3: Shane-title card

Figure 4: The Shooting-Gashade's hands

Figure 5: The Shooting-walking across desolate terrain

Figure 6: Two Lane Blacktop-Establishing shot, final sequence

\section{Works Cited}

Archer, N. The Road Movie: In Search of Meaning. London: Wallflower, 2016.

Atkinson, M. Crossing the Frontiers. Sight and Sound, pp. 14-17, 1994 é

Bazin, André. What Is Cinema?: Vol. 2. Translated by Hugh Gray, University of California Press, 1971.
Biskind, Peter. Easy Riders, Raging Bulls: How the Sex-Drugs-and-Rock-' $n$-Roll Generation Saved Hollywood. Simon \& Schuster, 1998.

Bogue, Ronald. Deleuze's Wake: Tributes and Tributaries. State University of New York Press, 2004.

Carmichael, Deborah A. The Landscape of Hollywood Westerns: Ecocriticism in an American Film Genre. University of Utah Press, 2006.

Cavell, Stanley and William Rothman. Cavell on Film. State University of New York Press, 2005.

de Certeau, M. The Practice of Everyday Life. Translated by Steven Rendall, University of California Press, 1984.

Cohan, Steven and Ina R. Hark. The Road Movie Book. Routledge, 1997.

Cooney, T. A. The Rise of the New York Intellectuals: Partisan Review and its Circle. University of Wisconsin Press, 1986.

Deleuze, Gilles, and Félix Guattari. Kafka: Toward a Minor Literature. Translated by Dana Polan, University of Minnesota Press, 1986.

---. A Thousand Plateaus: Capitalism and Schizophrenia. Translated by Brian Massumi, University of Minnesota Press, 2005.

Donaldson, Lucy F. Texture in Film. Palgrave Macmillan, 2014.

Elsaesser, Thomas. The Pathos of Failure: Notes on the Unmotivated Hero. In A. H. Thomas Elsaesser, The Last Great American Picture Show: New Hollywood Cinema in the 1970s (pp. 279-292). Amsterdam: Amsterdam University Press, 2004 
Engelmeier, P. Icons of film: the 2oth century. Munich: Prestel, 2000.

Feeney, M. Nixon at the Movies: A Book About Belief. Chicago: University of Chicago Press, 2004

Goldstein, D. L. The Automobile and American culture. Ann Arbor: University of Michigan Press, 1983

Harvey, T. Rainbow Bridge to Monument Valley: making the modern old West. Norman: University of Oklahoma Press, 2011.

Hellman, M., Director. The Shooting. Proteus Films, 1966.

Jackson, J. B. Discovering the Vernacular Landscape. Yale University Press, 1984.

Keathley, Christian. "Trapped in the Affection Image: Hollywood's Post-Traumatic Cycle 1970-1976." The Last Great American Picture Show: New Hollywood Cinema in the 1970s, edited by Thomas Elsaesser, Al- exander Horvath, and Noel King, Amsterdam University Press, 2004, pp. 293-308.

Laderman, David. Driving Visions: Exploring the Road Movie. University of Texas Press, 2002.

Poague, Leland A. Another Frank Capra. Cambridge University Press, 1994.

Rafelson, B., director. Five Easy Pieces. BBS Productions, 1970.

Schaefer, Dennis, and Salvato, Larry. Masters of Light: Conversations with Contemporary Cinematographers. University of California Press, 1984.

Stevens, George, director. Shane. Paramount Pictures, 1953.

Stoehr, M. L. Ride, Boldly Ride. University of Californi Press, 2012.

Tompkins, Jane P. West of Everything: The Inner Life of Westerns. Oxford University Press, 1992. 